\title{
Reasons for SFN Failure in Broadcast
}

\author{
Paulo E. R. Cardoso \\ Yuzo lano \\ Silvio R. M. Carvalho \\ Hermes J. Loschi \\ Fabiano G. S. Magrin \\ Diego A. P. Castro \\ Luiz A. S. Ferreira
}




\title{
Reasons for SFN Failure in Broadcast
}

\author{
Paulo E. R. Cardoso, Yuzo Iano, Silvio R. M. Carvalho, Hermes J. Loschi, \\ Fabiano G. S. Magrin, Diego A. P. Castro, and Luiz A. S. Ferreira
}

\begin{abstract}
To deliver the content of a TV network, ensuring efficient spectrum usage, filling not covered and shadow areas, and with energy savings are the advantages of Single Frequency Networks. Thus, in this study we sought to measure information, frequency, and time synchronism to evaluate the status of SFN implementation in Brazilian broadcasting. We took as base of analysis the Digital TV stations of the Campinas/SP area. Through this paper, we demonstrate that one of the great advantages of ISDB-Tb, the formation of a single frequency network, still cannot be implemented in Brazil.
\end{abstract}

Index Terms - Coverage, Digital Broadcast, Quality, SFN.

\section{INTRODUCTION}

$\mathrm{S}_{\mathrm{i}}^{\mathrm{F}}$ FNs are the solution for efficient spectrum usage; improvement of coverage in digital systems; and transmitters energy savings [1]. Efficient use of spectrum is achieved by replacing MFNs - Multiple Frequencies Networks, when an entity requires multiple channels to distribute its content to a particular region, by only one channel, allowing the other channels to be used by other entities. As with MFNs, but with efficient spectrum usage, overlapping service areas, as well as the use of gap-fillers for filling shadow areas allow the broadcaster to have greater control of where its signals are present, resulting in an improvement in the coverage of the entities. And the use of several stations and gap-fillers ends with the paradigm of high power [2], mainly derived from the analog legacy, where only one transmitting station covered the whole service area compared to several stations with lower transmission power generates an energy saving for the same coverage in SFN.

Brazil is currently at the beginning of the switch-off of the analog TV signal [3], in some cities only the signal with digital modulation is present. In this scenario, the next step in improving the broadcasting services quality is to guarantee coverage, which should be based on the efficient use of spectrum, the maximization of coverage, and energy efficiency, therefore the use of SFNs is fundamental for this next step.

P. E. R. Cardoso is a PhD Candidate in Electrical Engineer, researching in Laboratory of Visual Communications (LCV), Department of Communication (DECOM), Faculty of Electrical and Computer Engineering (FEEC), University of Campinas (Unicamp) - Campinas/SP - Brazil (perc@decom.fee.unicamp.br).

Y. Iano is a professor, founder of Laboratory of Visual Communications (LCV), in Department of Communication (DECOM), Faculty of Electrical and Computer Engineering (FEEC), University of Campinas (Unicamp) (yuzo@decom.fee.unicamp.br).
In this paper, we show the results of an evaluation, in the region of Campinas/SP, where we verified if the conditions for the implementation of SFNs are being respected. This evaluation considers technical, commercial, and regulatory aspects, and we show, in general, it is not yet possible to fully implement SFNs.

\section{SFN SOLUTION IN ISDB-TB}

\section{A. Technical}

A SFN is formed when two or more stations transmit the same content in a region of interest, at the same frequency. SFNs can be formed between transmitters (TX-TX), and between transmitters and gap-fillers (TX-GF) [4]. In the first case, the objective is to expand a coverage area, whereas in the second it is to eliminate shadow areas inside a transmitter coverage. Both solutions can be used by a broadcaster. Figure 1 illustrates these two possibilities.

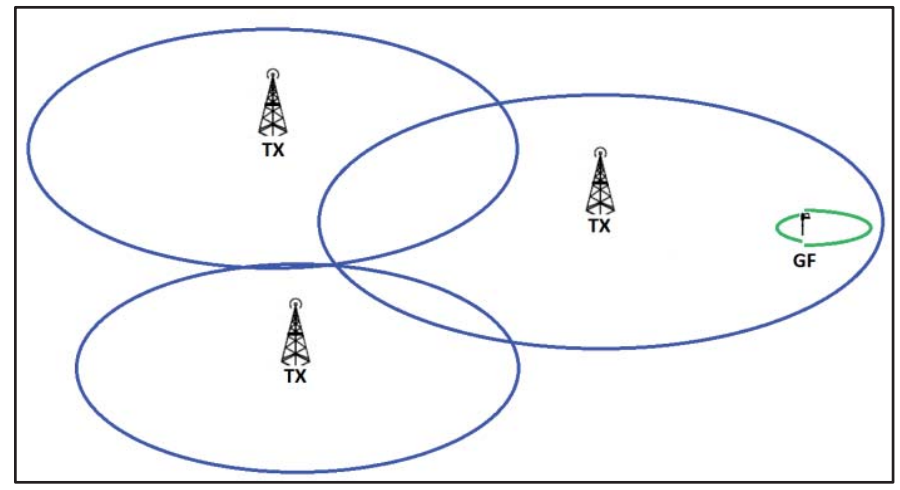

Fig. 1. TX-TX and TX-GF SFN.

We can also classify a SFN in Distributed, where the BTS Broadcast Transport Stream signal is received by all stations and is transmitted simultaneously, or with minor adjustments to fit the reception within the guard interval. It is necessary to synchronize the transmission in $1 \mathrm{pps}$ in these networks [1], which is obtained from the GPS synchronism (10 MHz); and in Repeated, in which a transmitter or gap-filler receives the signal

S. R. M. Carvalho is a post-doctorate researcher in LCV-DECOM-FEECUnicamp (e-mail: srcmessias@gmail.com).

H. J. Loschi is a PhD Candidate in Electrical Engineer, researching in LCVDECOM-FEEC-Unicamp (e-mail hermes@decom.fee.unicamp.br).

F. G. S. Magrin; is professor at the Federal University of Technology Parana, UTFPR, Campus Curitiba (magrin@utfpr.edu.br).

D. A. P. Castro and L. A. S. Ferreira are MSc Candidates in Electrical Engineer, researching in LCV-DECOM-FEEC-Unicamp (diegop@decom.fee.unicamp.br / luiz.ferreira@outlook.com). 
via air from another transmitter and retransmits it. The retransmitted signal already contains the delay corresponding to the path of the first transmitter to the second one where signal is retransmitting [2].

As they operate on the same frequency, potentially there are regions where the signals from several transmitters do not respect the $19 \mathrm{~dB}$ co-channel protection ratio determined by Resolution [5]. However, the BST-COFDM modulation, used in ISDB-Tb [6], allows the formation of single frequency networks, because the guard interval that guarantees immunity to intersymbol interference of reflections and multipath, can also be used to generate constructive combinations with the signals of several transmitters. In this case, the concern is no longer the difference of field strength between the signals of several transmitters, but rather the delay with which these signals are delivery to the receiver.

For SFN to work, there must be synchronism in frequency, that is, the same channel should be used; the temporal, the various transmissions must be received by the receiver within the guard interval; and of information, where each received QPSK, 16QAM, or 64QAM symbol must be identical [1] [3].

However, the use of SFN also entails some disadvantages [7]: The TS - Transport Stream must be equal in all transmitters of the network, forbidding the generation of local content; if any transmitter violates the rules of the network, it will act as a jammer, creating interference; and, finally, the need for synchronism, in time, frequency, and information.

\section{B. Laws and Regulation}

The channeling developed for Digital TV over the last years [8] has planned the adoption of the reuse frequency, i.e. the television networks occupy a same channel in certain regions of the country. This was the first attempt to adapt the regulation to the technological novelty allowed by SFN. This initiative was called Bus Channel.

With the needs for the new digital channel and simulcast, a re-channeling was carried out (both with the change of the analog channels and the inclusion of the digital, with possibility of using digital channels adjacent co-located) that the single channel was used for the digital content of a TV network (even) and the adjacent channel for the analog (odd) [8]. However, at this stage there was still the thought of a single station covering the entire service area of the entity. Reinforcers would be used only to cover shadow areas.

Updates of the legislation on Digital TV in Brazil, particularly the Portaria $n^{\circ}$ 932/2014 of MCTIC - Ministério da Ciência, Tecnologia, Inovações e Comunicações, foresee the implementation of SFNs [9]. This document allows the installation of stations within the service area of the main station, the gap-fillers, and additionally, allows retransmitter stations to be created outside the service area, but in the same channel, if this channel is unfeasible to be used by another entity [5] [9]. In Figure 2 we present a situation where it is not possible to include a station of the same frequency, but with a different content, because the Interferential Contour (red line) makes it impossible to include this station. In this case the entity that already holds the authorization of the three stations may request an additional station, to cover the area between existing stations.

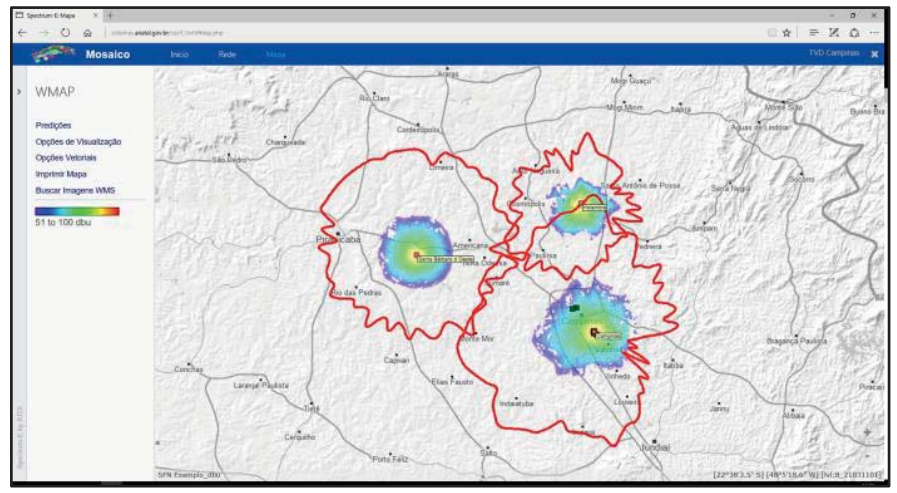

Fig. 2. "Unfeasible" Station inclusion inside a SFN.

In practice, the legislation authorizes the entity executing the television service to "fill" the empty spaces, whether they are shadow areas within the service area or uncovered areas between the service areas of the main stations of the same frequency and the same content, allowing the entity, through SFN, improve the coverage of its content by using several stations.

\section{SFN EVALUATION}

According to the conditions established for SFN, the transmission modes of each station composing a network must be identical, as well as the content, ensuring that the same symbol will be received by the receiver, within the guard interval. Thus, in this study we sought to measure the transmission modes and transmitted content (information synchronism), of each channel (frequency synchronism), verifying whether these conditions were met, allowing the execution of SFN. We also measured the delays of the various signals that were received, in some cases it is possible to determine if this signal is reflection / multipath or from another station of network, allowing to check if these signals are within the guard interval (time synchronism).

To evaluate the viability of SFN implementation in Brazilian broadcasting, we took as base of analysis the Digital TV stations of the city of Campinas/SP. According to Basic Plan of Anatel - Agência Nacional de Telecomunicações, there are 15 stations in Campinas/SP, of which 5 are generators (TVD) and 10 are re-transmitters (RTVD), with 12 currently in operation.

Evaluation points were chosen within the city of Campinas/SP and close to the theoretical average coverage limit of the stations of Campinas/SP, observing if the reception occurred through the station of Campinas/SP or another station in the same frequency of another city. As the channeling for Digital TV was developed on the concept of the Bus Channel, there are in the municipalities around Campinas/SP several stations forming a network of affiliations using the same channel. One of the objectives of this evaluation is to verify how these channels at the same frequency are being used for the distribution of the audiovisual content of a TV network.

We used the DIVICATCH ISDB-T/Tb device to measure the transmission modes, check the transmitted content and, the 
delays between the various received signals. This equipment allows you to measure RF signal parameters (Level, MER, SNR, BER), indicates the transmission modes (TMCC, Layers $\mathrm{A} / \mathrm{B} / \mathrm{C}$ ), and the constellation, besides allowing the decoding and recording of the transmitted content of the channel under analysis. The DIVICATCH ISDB-T/Tb was connected to the Schaffner UPA6192 antenna and measurements were taken at 2 meters from ground.

The coverage and interference simulations presented in this paper were performed in the ANATEL-MOSAICO System, which uses the approved installation data of each station and the Basic Plan of Anatel.

\section{RESUlts}

The geographical points where we perform the evaluation of the channels are shown in Figure 3.

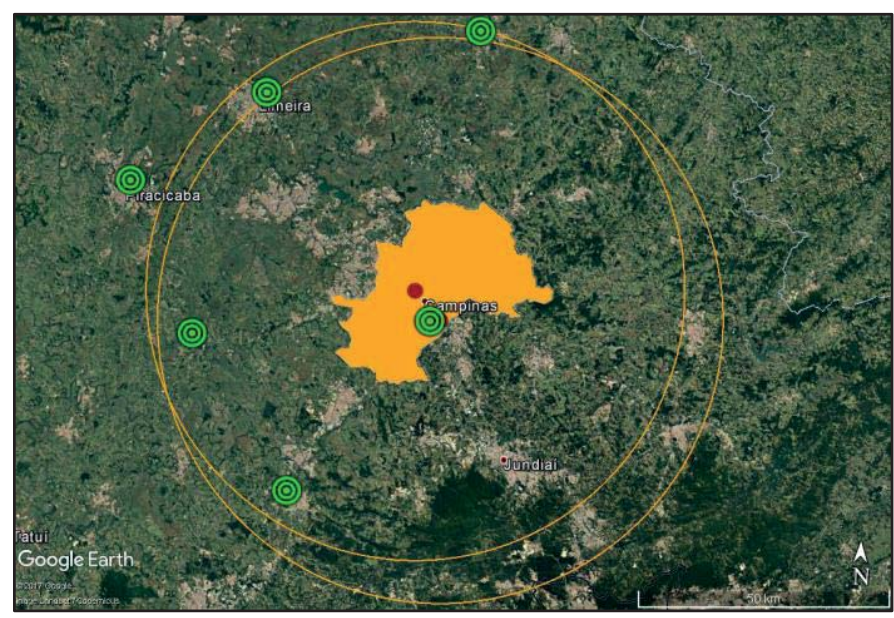

Fig. 3. Evaluation Points.

We chose six evaluation points, searching for a variability of possible alternative stations for reception. The points are in the cities and in the geographical coordinates:

Campinas/SP: $22^{\circ} \mathrm{S} 56^{\prime} 44.69^{\prime \prime} / 47^{\circ} \mathrm{W} 03^{\prime} 00.87^{\prime \prime}$,

Mogi-Mirim/SP: $22^{\circ} \mathrm{S} 25^{\prime} 38.80^{\prime \prime} / 46^{\circ} \mathrm{W} 58^{\prime} 31.70^{\prime \prime}$,

Limeira/SP: $\quad 22^{\circ} \mathrm{S} 33^{\prime} 04.20^{\prime \prime} / 47^{\circ} \mathrm{W} 22^{\prime} 55.30^{\prime \prime}$,

Piracicaba/SP: $\quad 22^{\circ} \mathrm{S} 42^{\prime} 56.10^{\prime \prime} / 47^{\circ} \mathrm{W} 38^{\prime} 19.70^{\prime \prime}$,

Capivari/SP: $\quad 22^{\circ} \mathrm{S} 59^{\prime} 00.90^{\prime \prime} / 47^{\circ} \mathrm{W} 30^{\prime} 31.00^{\prime \prime}$ " and

Itu/SP: $\quad 23^{\circ} \mathrm{S} 15^{\prime} 23.60^{\prime \prime} / 47^{\circ} \mathrm{W} 18^{\prime} 51.80^{\prime \prime}$.

At each measurement point, we point the directional antenna to the nearest transmission site as an attempt to receive the signal from the nearest station with greater intensity.

In TABLE I we present the transmission modes obtained in each point for each channel.
TABLE I

TRANSMISSION MODES AND CONTENT

\begin{tabular}{|c|c|c|c|c|c|c|c|}
\hline \multicolumn{2}{|c|}{ Channel Layer } & Campinas & itu & Limeira & Mogi-Mirim & Piracicaba & Capivari \\
\hline \multirow{2}{*}{1} & & QPSK $-2 / 3-1 / 8$ & QPSK $-2 / 3-1 / 8$ & QPSK - $2 / 3-1 / 8$ & QPSK $-2 / 3-1 / 8$ & QPSK - $2 / 3-1 / 8$ & QPSK - $2 / 3-1 / 8$ \\
\hline & B & $160 \mathrm{AM}-7 / 8-1 / 8$ & $160 A M-7 / 8-1 / 8$ & $160 A M-7 / 8-1 / 8$ & $160 A M-7 / 8-1 / 8$ & $160 A M-7 / 8-1 / 8$ & $160 A M-7 / 8-1 / 8$ \\
\hline \multirow{2}{*}{ "I } & A & QPSK - $2 / 3-1 / 8$ & QPSK $-2 / 3-1 / 8$ & QPSK - $2 / 3-1 / 8$ & & QPSK - $2 / 3-1 / 8$ & QPSK $-2 / 3-1 / 8$ \\
\hline & B & $16 Q A M-2 / 3-1 / 8$ & 16QAM - $2 / 3-1 / 8$ & 16 AAM - $2 / 3-1 / 8$ & & $16 \mathrm{AMM}-2 / 3-1 / 8$ & $160 A M-2 / 3-1 / 8$ \\
\hline \multirow[b]{2}{*}{ III } & A & QPSK - $2 / 3-1 / 8$ & QPSK $-2 / 3-1 / 8$ & QPSK - $2 / 3-1 / 8$ & QPSK-2/3-1/8 & QPSK-2/3-1/8 & \\
\hline & B & $64 Q A M-3 / 4-1 / 8$ & $640 A M \cdot 3 / 4 \cdot 1 / 8$ & 64QAM - 3/4-1/8 & 64QAM - 3/4-1/8 & 64QAM - 3/4-1/8 & - \\
\hline \multirow{2}{*}{ IV } & A & QPSK - $2 / 3-1 / 8$ & QPSK - $2 / 3 \cdot 1 / 8$ & QPSK - 2/3 - 1/8 & QPSK - $2 / 3-1 / 8$ & QPSK - $2 / 3 \cdot 1 / 8$ & . \\
\hline & B & $64 Q \mathrm{QAM}-3 / 4-1 / 8$ & $160 A M-1 / 2-1 / 8$ & 160 AM - $1 / 2-1 / 8$ & $160 A M-1 / 2-1 / 8$ & $160 A M-1 / 2-1 / 8$ & \\
\hline \multirow{2}{*}{ v } & A & QPSK - $2 / 3-1 / 16$ & QPSK - $2 / 3-1 / 16$ & - & QPSK- $2 / 3-1 / 8$ & 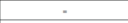 & QPSK - 2/3-1/16 \\
\hline & B & $64 Q A M-3 / 4-1 / 16$ & 640AM - 3/4-1/16 & & $160 A M-7 / 8-1 / 8$ & & 64QAM - 3/4-1/16 \\
\hline \multirow[b]{2}{*}{ vi } & A & QPSK - $2 / 3-1 / 8$ & QPSK - $2 / 3-1 / 8$ & QPSK - $2 / 3-1 / 8$ &. & QPSK - 3/4-1/16 & . \\
\hline & B & $160 A M-2 / 3-1 / 8$ & $160 \mathrm{AM}-2 / 3-1 / 8$ & 64 QAM - $3 / 4-1 / 8$ & - & 64OAM - 3/4-1/16 & - \\
\hline \multirow{2}{*}{ VII } & A & QPSK - $2 / 3-1 / 4$ & QPSK - $2 / 3-1 / 4$ & QPSK- $2 / 3-1 / 4$ & 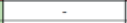 & 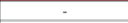 & - \\
\hline & B & $160 A M-3 / 4-1 / 4$ & $160 A M-3 / 4-1 / 4$ & $160 \mathrm{AM}-3 / 4-1 / 4$ & - & - & - \\
\hline \multirow{2}{*}{ VII } & A & QPSK $-2 / 3-1 / 8$ & QPSK $-2 / 3-1 / 8$ & & - & - & - \\
\hline & B & $64 Q A M-3 / 4-1 / 8$ & $640 \mathrm{AM}-3 / 4-1 / 8$ & - & - & - & - \\
\hline \multirow{2}{*}{$\mathrm{IX}$} & A & QPSK - $2 / 3-1 / 16$ & QPSK - $2 / 3-1 / 16$ & - & - & - & - \\
\hline & B & $16 Q A M=3 / 4-1 / 16$ & $160 A M \cdot 3 / 4-1 / 16$ & - & - & - & - \\
\hline \multirow{2}{*}{$\mathrm{x}$} & A & QPSK - $2 / 3-1 / 8$ & QPSK - $2 / 3-1 / 8$ & - & - & - & - \\
\hline & B & $16 \mathrm{QAM}-2 / 3-1 / 8$ & $160 A M-2 / 3-1 / 8$ & & - & - & - \\
\hline \multirow{2}{*}{$\mathrm{x} \mathbf{x}$} & $\mathrm{A}$ & QPSK - $2 / 3-1 / 16$ & & QPSK - 2/3-1/16 & . & - & . \\
\hline & B & $64 \mathrm{QAM}-3 / 4-1 / 16$ & & 640AM - 3/4-1/16 & - & - & - \\
\hline \multirow{2}{*}{ XII } & A & QPSK - $2 / 3-1 / 16$ & QPSK - $2 / 3-1 / 8$ & - & - & 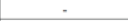 & . \\
\hline & B & $640 A M-3 / 4-1 / 16$ & $160 \mathrm{AM}-2 / 3-1 / 8$ & - & - & - & - \\
\hline \multirow{2}{*}{ xIIII } & A & QPSK - $2 / 3-1 / 16$ & - & - & - & - & - \\
\hline & 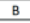 & $64 Q A M-3 / 4-1 / 16$ & - & - & & $\theta$ & 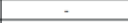 \\
\hline \multirow{2}{*}{ XIV } & A & & - & - & QPSK - $2 / 3-1 / 8$ & - & - \\
\hline & B & - & - & - & $160 A M-2 / 3-1 / 8$ & - & - \\
\hline \multirow{2}{*}{$x v$} & A & & & - & & - & - \\
\hline & & & & & & & \\
\hline
\end{tabular}

We note that the TMCC information (Transmission and Multiplexing Configuration Control signal loads all the information of the transmission modes, and must be sent by a specific carrier to assist in the identification of the operating modes by receiver.) was decoded in just under half of the possibilities. The non-decoding of the TMCC can be explained by the inexistence of the transmitting station in the channel near the measurement point and by the low signal strength of more distant stations.

In TABLE I, the gray ones mark the receptions taken as reference for each channel, almost all are stations installed and transmitting from Campinas/SP. In the case of channel XI we verified that this one is installed in the city of Limeira/SP and the station of this channel in Campinas/SP is not yet in operation, so, the reception in Campinas/SP was of the signal coming from Limeira/SP. For channel XIV, reception was only possible in Mogi-Mirim/SP. It was not possible to decode channel XV at any of the measured points.

In yellow are indicated the receptions that despite being obtained in a municipality different from the reference, were obtained from the reference station signals. In green are the station receptions different from the reference station and with transmission modes and content identical of the reference station. The formation of SFN among the receptions highlighted in gray, yellow, and green is possible.

The receptions highlighted in orange are from another station, with the same content, but with different transmission modes. And in red are highlighted the receptions in which there are differences in the content. In these cases, SFN formation is not possible.

We show the measurements of the echoes in TABLE II. We present the worst-case scenario, that is, the echo with the lowest attenuation (in $\mathrm{dB}$ ) in relation to the main signal (with the highest intensity) and the delay (in $\mu \mathrm{s}$ ). 
TABLE II

ATTENUATION AND DELAY OF ECHOES

\begin{tabular}{|c|c|c|c|c|c|c|}
\hline Channel & Parameter & Campinas & Itu & Limeira & Piracicaba & Capivari \\
\hline \multirow{2}{*}{1} & Attenuation (dB) & 33.50 & 15.70 & 25.5 & 24.20 & 21.40 \\
\hline & Delay $(\mu \mathrm{s})$ & 7.88 & 3.94 & 21.00 & 6.56 & 26.25 \\
\hline \multirow{2}{*}{ " } & Attenuation (dB) & 36.80 & 24.30 & 30.9 & 20.80 & - \\
\hline & Delay $(\mu \mathrm{s})$ & 9.19 & 3.94 & 13.12 & 6.56 & - \\
\hline \multirow{2}{*}{ III } & Attenuation (dB) & 38.30 & 7.60 & 27.90 & 19.10 & - \\
\hline & Delay $(\mu s)$ & 6.56 & 2.63 & 22.31 & 9.19 & - \\
\hline \multirow{2}{*}{ IV } & Attenuation (dB) & 32.70 & 32.40 & 30.80 & 16.50 & - \\
\hline & Delay $(\mu s)$ & 9.19 & 7.88 & 14.44 & 7.87 & 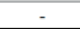 \\
\hline \multirow{2}{*}{ v } & Attenuation (dB) & 38.10 & 23.40 & - & 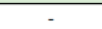 & 26.60 \\
\hline & Delay $(\mu \mathrm{s})$ & 10.50 & 14.44 & - & - & 3.94 \\
\hline \multirow{2}{*}{ vi } & Attenuation (dB) & - & 8.80 & 32.90 & 20.10 & - \\
\hline & Delay $(\mu \mathrm{s})$ & - & -210.00 & 22.31 & 7.88 & - \\
\hline \multirow{2}{*}{ VII } & Attenuation (dB) & 38.00 & 9.30 & 31.00 & - & - \\
\hline & Delay $(\mu s)$ & 9.19 & 2.62 & 22.31 & - & - \\
\hline \multirow[b]{2}{*}{ VIII } & Attenuation (dB) & 35.00 & 17.60 & - & - & - \\
\hline & Delay $(\mu \mathrm{s})$ & 6.56 & 3.94 & - & - & - \\
\hline \multirow{2}{*}{ IX } & Attenuation (dB) & 32.60 & 12.00 & - & - & - \\
\hline & Delay $(\mu \mathrm{s})$ & 3.94 & 2.63 & - & - & - \\
\hline \multirow{2}{*}{$x$} & Attenuation (dB) & 28.90 & 10.20 & - & - & - \\
\hline & Delay $(\mu s)$ & 7.88 & 2.63 & 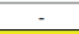 & - & - \\
\hline \multirow[b]{2}{*}{$\mathbf{X I}$} & Attenuation (dB) & 30.90 & - & 17.80 & - & - \\
\hline & Delay $(\mu s)$ & -85.31 & - & 13.13 & - & - \\
\hline \multirow{2}{*}{ XII } & Attenuation (dB) & 21.20 & 9.90 & - & - & - \\
\hline & Delay $(\mu s)$ & -19.69 & 2.63 & - & - & - \\
\hline \multirow{2}{*}{ XIII } & Attenuation (dB) & 37.30 & - & - & - & - \\
\hline & Delay $(\mu s)$ & 5.25 & - & - & - & - \\
\hline \multirow{2}{*}{ XIV } & Attenuation (dB) & - & - & - & - & - \\
\hline & Delay $(\mu \mathrm{s})$ & - & - & - & - & - \\
\hline \multirow{2}{*}{$x v$} & Attenuation (dB) & - & 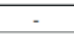 & - & - & - \\
\hline & Delay $(\mu s)$ & - & - & - & - & - \\
\hline
\end{tabular}

The situation where the echo respects both the protection ratio and the guard interval is highlighted in green; yellow highlights when the protection ratio is not respected, but the guard interval is. In these situations, it is possible the formation of SFN. In red we highlight the situation where neither the protection ratio nor the guard interval are respected, causing the intersymbol interference and not allowing the formation of SFN.

\section{DisCUSSIONS}

Observing the results of TABLE I, we verified that channels VIII, IX, X, XI, XIII, and XIV had only one station in operation and together with channel XV, which has no station in operation, so it is not possible to evaluate the formation of SFN for these 7 channels.

Channels I, II, III, and VII have more than one station in operation and both the transmission configuration and the content are identical, guaranteeing the synchronism of information, i.e. the same symbol arrives at the receiver. In TABLE II we observe that these channels also have the temporal synchronism, therefore the SFN can be implemented without any problem.

Since we did not measure the information on programmed transmission delays on the transmitters, which defines, in the interests of the broadcaster, the areas where there will be reception of signals with echoes outside the guard interval, it is not possible to simulate the real situation of the coverage of channels I, II, III, and VII. This is a technical freedom offered by SFN and has not yet been regulated by Brazilian legislation.

In relation to channels $\mathrm{IV}, \mathrm{V}, \mathrm{VI}$, and XII, we observe that there is no synchronism of information, because or the setting of transmission modes (IV and $\mathrm{V}$ channels) or the content (channels VI and XII) is different between stations of the same frequency, impeding the implementation of SFN.
In the case of channels IV and V, with configuration of the different transmission modes between the stations, this is a merely technical problem, where simple standardization quickly solves the problem. However, this difference causes the station of Campinas/SP, in the case of channel IV, to operate as a jammer, causing mutual interference with other network stations. In Figure 4, we present the simulation of this interference, showing its extension, which has a very large area when compared to the simulation of the coverage desired through the SFN, shown in Figure 5.

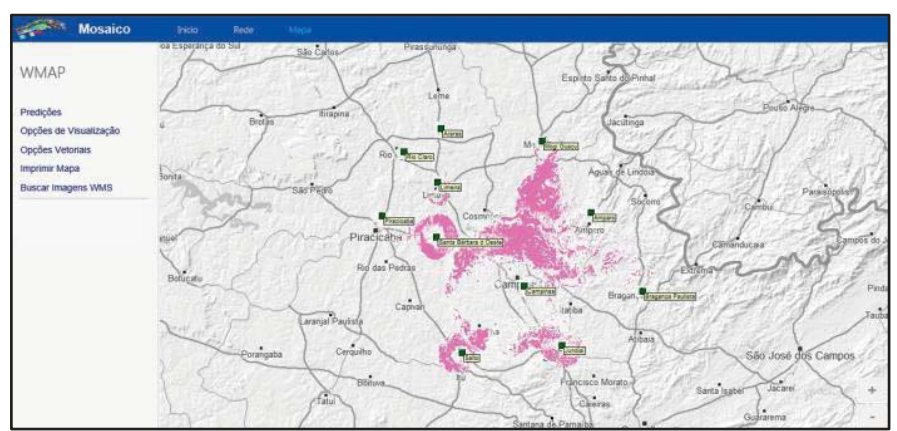

Fig. 4. "Jammer" station of channel IV in Campinas/SP.

As the Campinas/SP station is configured with transmission modes different from the others, the received symbols are different, in this way signals that do not respect the protection ratio of $19 \mathrm{~dB}$ become interfering. And the entire area highlighted in Figure 4 no longer has the reception of channel IV, implying in the loss of network quality.

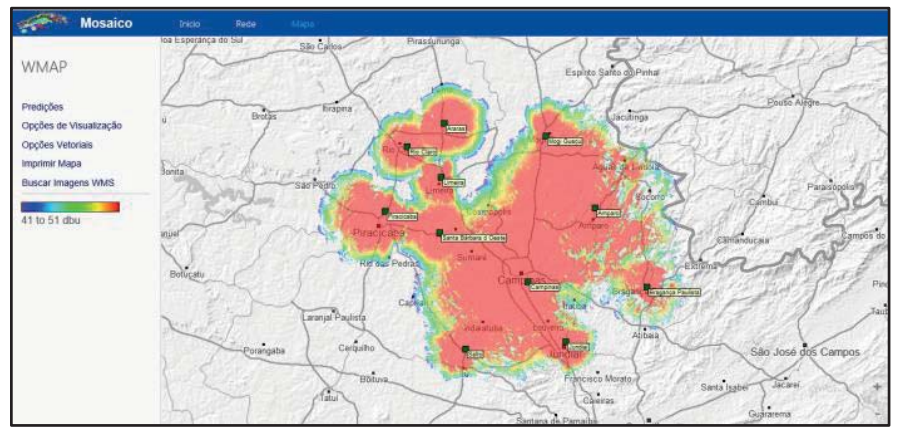

Fig. 5. SFN Coverage of channel IV.

We present in Figure 5 the simulation of the coverage of the stations of channel IV, if the SFN was configured correctly. In red, signals with field strength above $51 \mathrm{~dB} \mu \mathrm{V} / \mathrm{m}$ are presented.

In the case of channels VI and XII, the transmission of different contents also causes a region with interferences, as demonstrated previously, but the cause of this problem ceases to be technical and passes to the commercial / business sphere.

When the digital channeling and the use of the Bus Channel were planned, the current entity of channel $\mathrm{V}$ station of Campinas/SP has been assigned to occupy the channel VI. After the channeling, there was a contractual change between networks and the Campinas/SP station started to have a different content.

As the stations of the $\mathrm{V}$ and VI channels in Campinas/SP have different technical characteristics it is not possible, from 
the regulatory point of view, to change the technical characteristics of the whole network to maintain the possibility of SFN. In this case, the execution of the SFN is really compromised, since the content of this entity began to be distributed by an MFN.

Additionally, we measured the echoes for each channel at points between stations. Figure 6 shows a situation in which there is an echo with attenuation of $-0.6 \mathrm{~dB}$ relative to the main signal, a case where the protection ratio is not being respected, but the delay is $17.06 \mu \mathrm{s}$, respecting the guard interval. The content was decoded in this situation.

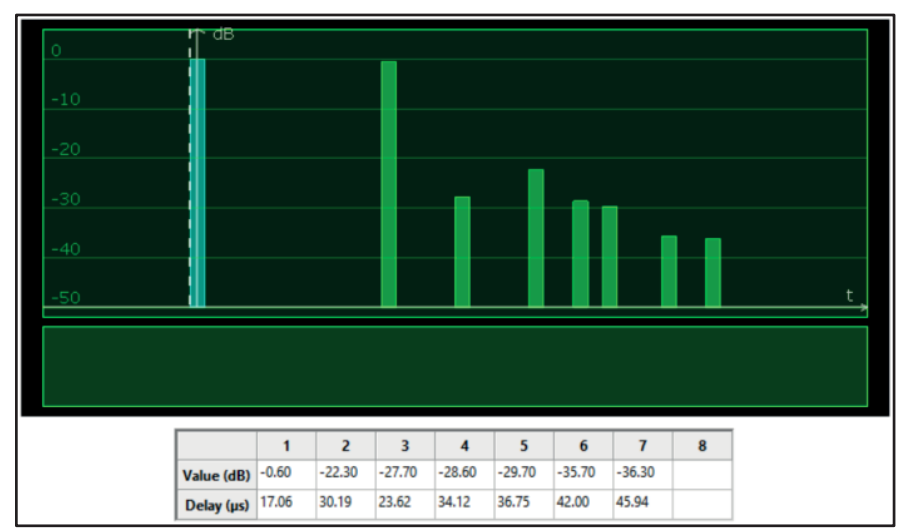

Fig. 6. Echoes inside Guard Interval.

We took the opportunity to illustrate, through Figure 7, the situation where there is no content decoding: when the echoes reach the highlighted region in pink of the graph, neither the protection ratio nor the guard interval were respected.

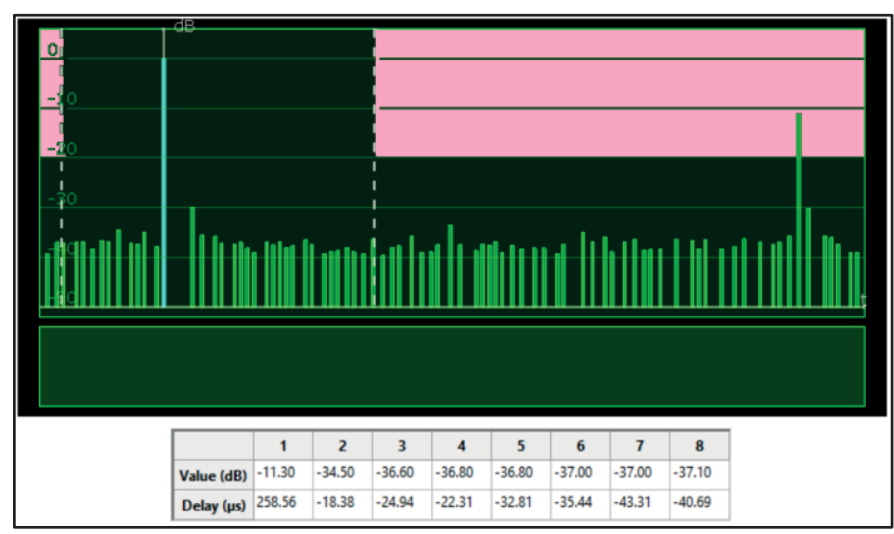

Fig. 7. Echoes in SFN with ISI.

In Figure 7 we pointed to an echo that is attenuated at only $11.3 \mathrm{~dB}$, thus interfering, and delayed at $258.56 \mu$ s, i.e., outside the guard interval (dashed lines). In this case intersymbol interference occurs.

In some cases, it was possible to observe the echoes coming from other stations within the guard interval. Figure 8 shows the situation described.

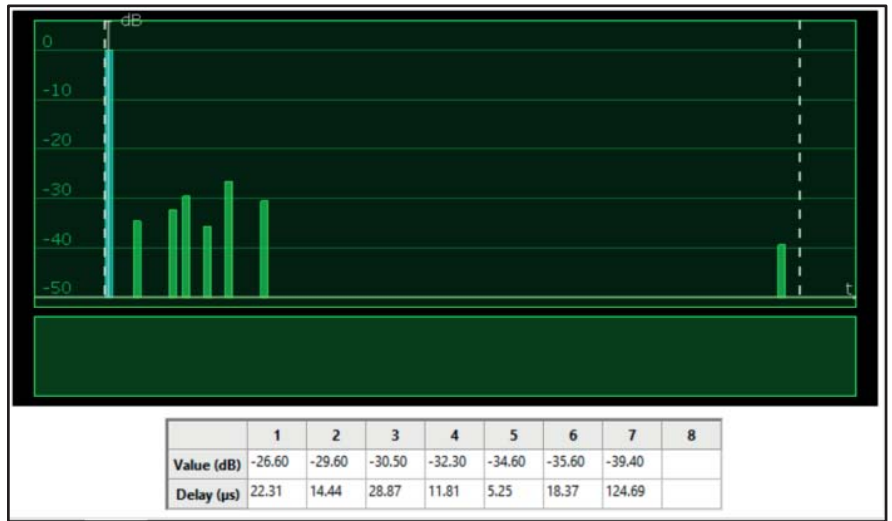

Fig. 8. Echoes in SFN from different stations.

In Figure 8, obtained in Limeira/SP, we observed almost at the limit of the guard interval the signal coming from the station of Campinas/SP. In this case, the directional antenna used in the evaluation was pointed to the Campinas/SP station, so the blue signal, which is the main signal of the station of Limeira/SP, despite having a higher intensity, was still attenuated by the antenna front-back ratio, which is $15 \mathrm{~dB}$. The content was decoded at this reception. It is noteworthy that as the measurement presented in Figure 8 was collected at a position close to the Limeira/SP station, the signal strength of the Campinas/SP station is below the limit of the protection ratio, which would not cause interference in any way despite being within the guard interval.

\section{CONCLUSION}

For a single frequency network to work, it is essential that the same channel being used, that the settings being identical and that the same content being transmitted, all within the guard interval. In the tests performed we observed that several of these conditions were not respected by the stations of the Campinas/SP region.

Through this paper, we demonstrate that one of the great advantages of ISDB-Tb, the formation of a single frequency network, still cannot be implemented in Brazil.

We conclude that for the implementation of SFNs the following points should still be improved:

- Technical training of the teams to configure the network;

- Stable commercial contracts between the generators of the network;

- Regulatory changes that do not tie the technical characteristics of the network stations.

In this sense, despite recent improvements, the regulation of Digital TV in Brazil still needs improvements. We have pointed to Portaria $n^{\circ} 932 / 2014$ as a beneficial approximation of technical needs with legislation, but the concept of main station is still very much present in the legislation. It is necessary to change the current standards so the main station, whose technical characteristics are authorized and inspected by the granting authority (Anatel and MCTIC), can be subdivided and distributed in several stations, being that the regulator would worry about the limits of the area of service rendering and with the possible interferences generated by the stations. 


\section{ACKNOWLEDGMENT}

The authors would like to thank the Agência Nacional de Telecomunicações (ANATEL), the Coordenação de Aperfeiçoamento de Pessoal de Nível Superior (CAPES), the Conselho Nacional de Desenvolvimento Científico e Tecnológico (CNPq), the Fundação de Amparo à Pesquisa do Estado de São Paulo (FAPESP), the Faculdade de Engenharia Elétrica e de Computação (FEEC), and the Universidade Estadual de Campinas (UNICAMP) for their support in the development of this research.

The authors also would like to thank the YOUCAST team, in special Raul Faller for their valuable contribution to this research.

\section{REFERENCES}

[1] A. Mattsson, Single Frequency Networks in DTV, IEEE Transactions on Broadcasting, Vol. 51, $\mathrm{N}^{\circ}$. 4, Dec. 2005.

[2] S. R. M. Carvalho, Contribuições para Melhoria na Confiabilidade de Redes de Frequência Única em Sistemas de Transmissão de TV Digital, Tese de Doutorado, Universidade Estadual de Campinas, Jul. 2014.

[3] Portaria $\mathrm{n}^{\circ}$ 2.992, Ministério da Ciência, Tecnologia, Inovações e Comunicações - Estabelece o cronograma de transição da transmissão analógica dos serviços de radiodifusão de sons e imagens e de retransmissão de televisão para o SBTVD-T, 26/05/2017.

[4] J. F. Rehme, and M. A. Martins, Cobertura de TV Digital com uso de redes MFN e SFN, Revista da SET, n 149, Mar. 2015.

[5] Resolução Anatel n ${ }^{\circ} 398$, Aprova as alterações do Regulamento Técnico para Emissoras de Radiodifusão Sonora em Frequência Modulada, e do Regulamento Técnico para a Prestação do Serviço de Radiodifusão de Sons e Imagens e do Serviço de Retransmissão de Televisão, 07/04/2005.

[6] M. Takada and M. Saito, Transmission systems for ISDB-T, Proceedings of the IEEE, Special Issue on Global Digital Television: Technology and Emerging Services, pp. 251-256, Jan. 2006.

[7] F. Rottensteiner, Technical Realisation of Digital TV Transmitter Systems, ITU inter-regional seminar, Kiev, Ukraine, 13-15 Nov. 2000

[8] T. Mondino, and V. Donzelli, Canalization Study For Digital TV in Brazil, Revista da SET, English Special Edition, Mar. 2010.

[9] Portaria $n^{\circ}$ 932, Ministério da Ciência, Tecnologia, Inovações e Comunicações, Aug. 2014

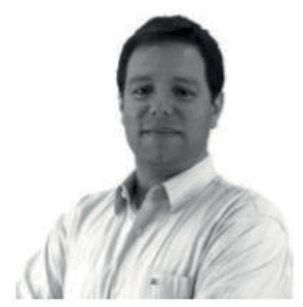

Paulo Eduardo dos Reis Cardoso. Holds a degree in Electrical Engineering from the FEECUNICAMP (2002) and a MSc degree in Electrical Engineering (Electronics) by DEMIC-FEEC-UNICAMP (2005). $\mathrm{He}$ is currently a $\mathrm{PhD}$ candidate in the LCV-DECOM-FEEC-UNICAMP, searching Digital TV. Licensed from the post of Specialist in Regulating in the Anatel, where it operates in coordination of grants and resources to the provision, working with the licensing and amendment of technical characteristics of broadcasting stations. Previously, he served in the surveillance in broadcasters. He was responsible for the Technical Regulation to Broadcasting in Modulated Frequency and analysis of processes of technical feasibility for inclusion or amendment of the Basic Plan of Distribution Channels of Broadcasting in Modulated Frequency. He participated as an observer in the Federal Government in testing of Digital Radio Broadcasting, both in tests of American Standard - HD Radio, in 2008 and 2012, as in tests of the European standard - DRM, in 2010. He has worked as a telecommunications researcher of the Fundação Centro de Pesquisas e Desenvolvimento - CPqD.

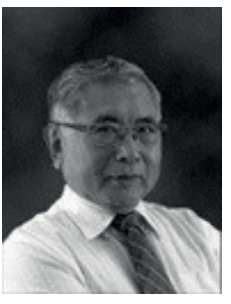

Yuzo Iano. Bachelor's at State University of Campinas/SP/Brazil-Unicamp in Electrical Engineering (1972), master's at Electrical Engineering from State University of Campinas (1974) and doctorate at Electrical Engineering from the same university (1986). He is currently full professor at Unicamp. Has experience in Electrical Engineering, focusing on Telecommunications, Electronics, and Information Technology. He is working in the following subjects: digital transmission and processing of images/audio/video/data, hdtv, digital television, networks 4G/5G, middleware, transmission, canalization, broadcasting of television signals, pattern recognition, digital coding of signals, data transmission and storage, and smart/digital cities.

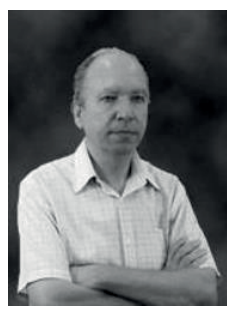

Silvio Renato Messias de Carvalho. Obtained his B.Sc degree in Electrical Engineering at UNICAMP (1994). Holds a MSc degree (2007) and a PhD degree (2013) in Electrical Engineering from UNICAMP as well. Research Interests: Audio and video for digital TV, broadcast engineering, digital TV engineering, RF systems, mobile TV, antennas, and Energy Efficiency.

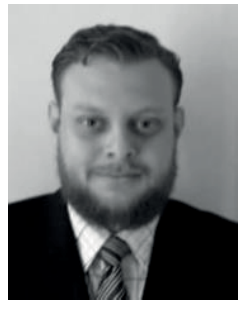

Hermes José Loschi. Holds MSc degree in Electrical Engineering (State University of Campinas - 2017) and Graduated in Control and Automation Engineering (Paulista University - 2014). Currently he is a PhD Candidate by Department of Communications, Faculty of Electrical and Computer Engineering at State University of Campinas, and a researcher at the laboratory of visual communications (LCV). The main topics of interest are Wireless Sensor Network, Internet of Things, Smart Grid, Broadcasting, Biomass, Photovoltaic Systems Applications, Solar Energy, Photovoltaic Solar Generation Prediction Systems and Solar Tracking.

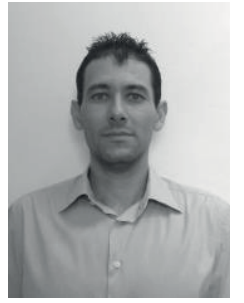

Fabiano Gustavo Silveira Magrin $\mathrm{He}$ received his bachelor's degree in electrical engineering in 2003, a master's degree in electrical engineering in 2014, and the $\mathrm{PhD}$ title in electrical engineering in 2017, all from University of Campinas, UNICAMP. He finished the graduation among the 10 best students of his class and obtained the Certificate of Studies in Electrical Energy Systems. He lived for more than a year in Dresden, Germany, where he gathered international experience during his graduation. From 2003 to 2012 he worked in the market as a field and application engineer in private companies and in protection relay manufacturers. Also during this period, he was responsible for theoretical protection courses, equipment training and worked with simulations in real time. The main research areas include transformer protection, protection and control of regular and half-wavelength transmission lines, development of protection 
and control algorithms, electromagnetic transient studies and real-time simulation. Currently, he is professor at the Federal University of Technology - Parana, UTFPR, Campus Curitiba.

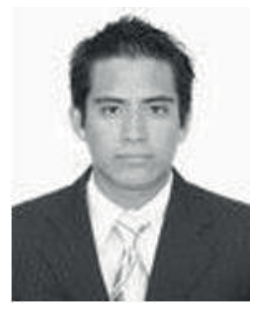

Diego Arturo Pajuelo Castro Graduate in Electrical Engineering from the Universidad Peruana de Ciencias Aplicadas (UPC), Lima, Peru in 2012. He is currently working towards his Master degree in Sciences and Telecommunications UNICAMP. Research Interests: Video and audio coding, Image processing, Digital television and Satellite communications.

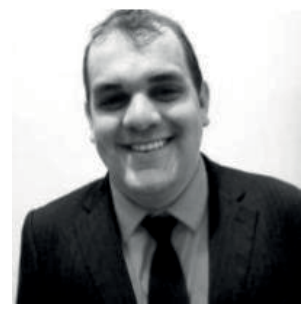

Luiz Antonio de Sousa Ferreira. Graduated in Computer Science at Pontifical Catholic University of Minas Gerais - PUC Minas (2015). Currently a M.Sc Candidate by Department of Communications, Faculty of Electrical and Computer Engineering at Unicamp. Research Interests: Wireless Network, Smart Grid, Photovoltaic Systems Applications, Telecommunications, Digital Signal Processing (Image and Video), Digital TV, and HDTV. 